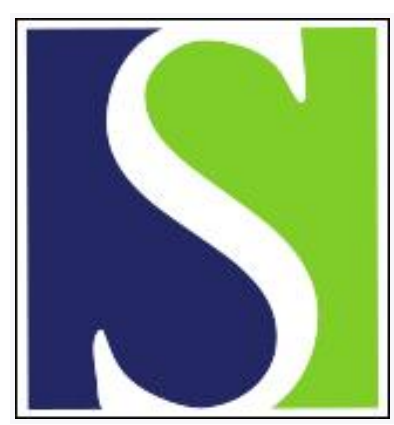

Scand J Work Environ Health 2014;40(1):100

https://doi.org/10.5271/sjweh.3391

Published online: 11 Oct 2013, Issue date: 01 Jan 2014

What is the true prevalence of carpal tunnel syndrome among US workers?

by Luckhaupt SE, Sweeney MH, Sestito JP, Calvert GM

Affiliation: National Institute for Occupational Safety and Health, 4676 Columbia Parkway, R-17, Cincinnati, OH 45226. sluckhaupt@cdc.gov

Refers to the following text of the Journal: 2013;39(5):495-505

Key terms: carpal tunnel syndrome; prevalence; surveillance

This article in PubMed: www.ncbi.nlm.nih.gov/pubmed/24121819 


\section{What is the true prevalence of carpal tunnel syndrome among US workers?}

By pooling data from six studies that participated in the Upper-Extremity Musculoskeletal Disorder Consortium (UEMSD), Dale et al's recent publication "Prevalence and incidence of carpal tunnel syndrome in US working populations: pooled analysis of six prospective studies" (1) provides an important contribution to the literature on carpal tunnel syndrome (CTS) among US workers. Although the main purpose of the UEMSD was not to estimate the national prevalence of CTS but rather to evaluate the relationship between workplace factors and upper-extremity health outcomes, Dale et al's reported baseline prevalence rate of CTS (7.8\%) might be considered one of the best estimates of the true prevalence of CTS among US workers performing hand-intensive activities.

Another recently published estimate of the prevalence of CTS among US workers is based on data collected through an Occupational Health Supplement (OHS) to the 2010 National Health Interview Survey (NHIS) (2). The 2010 NHIS-OHS asked participants if a clinician had ever diagnosed them as having CTS, and, if so, whether they had CTS in the past 12 months. According to the 2010 NHIS-OHS, the 12-month prevalence of self-reported clinician-diagnosed CTS among current/recent workers is $3.1 \%$, or 4.8 million workers. Clinicians attributed almost two thirds of these cases to work (2).

There are several reasons why the 12 -month prevalence estimate based on the 2010 NHIS-OHS is substantially lower than the baseline prevalence of CTS in the UEMSD study. Dale et al mention two of the main reasons: "While CTS rates depend on the physical exposures and other characteristics of the population under study, they are also affected by the study design and CTS case definitions used to define the disease." The UEMSD study population was not designed to be representative of the US population but instead had a high proportion of participants employed in manufacturing and other hand-intensive jobs. However, the UEMSD study assessed all participating workers and used a rigorous case definition of CTS that was based on symptoms and electrodiagnostic studies. In contrast, the NHIS-OHS sample was designed to be representative of the US adult population. For this reason, the prevalence estimate based on the NHIS-OHS would be expected to be a more accurate national estimate. However, since the 2010 NHIS-OHS estimate is based on self-reported clinician diagnoses of CTS, it has several limitations including: (i) it did not capture workers with CTS who did not seek healthcare or were misdiagnosed; (ii) no information was available on how the clinician made the CTS diagnosis; and (iii) there was total reliance on the worker's memory to accurately recall the CTS diagnosis.

This comparison highlights the need to employ multiple methods to understand the true burden of common work-related disorders in the general population. The 2010 NHIS-OHS and UEMSD estimates probably bookend the true national prevalence of CTS among workers, as it likely lies somewhere between the $3.1 \%$ and $7.8 \%$ estimates from the 2010 NHIS-OHS and the UEMSD study, respectively.

\section{References}

1. Dale AM, Harris-Adamson C, Rempel D, Gerr F, Hegmann K, Silverstein B, Burt S, Garg A, Kapellusch J, Merlino L, Thiese MS, Eisen EA, Evanoff B. Prevalence and incidence of carpal tunnel syndrome in US working populations: pooled analysis of six prospective studies. Scand J Work Environ Health. 2013;39(5):495-505. http://dx.doi.org/10.5271/sjweh.3351

2. Luckhaupt SE, Dahlhamer JM, Ward BW, Sweeney MH, Sestito JP, Calvert GM. Prevalence and work-relatedness of carpal tunnel syndrome in the working population, United States, 2010 National Health Interview Survey. Am J Ind Med. 2013;56(6):615-24. http://dx.doi.org/10.1002/ajim.22048

Sara E Luckhaupt, MD, MPH, 1, 2 Marie H Sweeney, PhD, MPH, ${ }^{1}$ John P Sestito, JD, MS, ${ }^{1}$ Geoffrey M Calvert, $M D, M P H^{1}$

${ }^{1}$ Division of Surveillance, Hazard Evaluations and Field Studies, National Institute for Occupational Safety and Health, Centers for Disease Control and Prevention, Cincinnati, Ohio

2 Correspondence to: Sara E Luckhaupt, National Institute for Occupational Safety and Health, 4676 Columbia Parkway, R-17, Cincinnati, $\mathrm{OH} 45226$ [E-mail: sluckhaupt@cdc.gov] 